NOBRE, Carlos Eduardo. Cartografia da ação: ocupações de vazios urbanos pelos movimentos de sem-teto...

\title{
Cartografia da ação: ocupações de vazios urbanos pelos movimentos de sem-teto de Maceió, AL (1999-2009)
}

\author{
Cartography of action: occupations of vacant urban spaces by homeless \\ movements in Maceió, AL (1999-2009)
}

http://dx.doi.org/10.5007/2178-4582.2015v49n1p120

\author{
Carlos Eduardo Nobre \\ Universidade Estadual de Campinas, Campinas/SP, Brasil
}

\begin{abstract}
Apresentamos uma descrição das ações de ocupação de vazios urbanos engendradas por dois movimentos de sem-teto que atuaram na década de 2000, na cidade de Maceió, Alagoas. Propomos uma leitura das ocupações a partir do instrumento Cartografia da Ação.. Tal leitura nos permite apreender a um só tempo a localização dos objetos - vazios urbanos -; as ações dirigidas pelos sem-teto - as ocupações -; e os deslocamentos espontâneos e compulsórios dessa população mediante a realocação das famílias para conjuntos habitacionais implantados pelos órgãos públicos da prefeitura e do governo do estado. A partir do registro dos deslocamentos, vislumbra-se uma cartografia da ação, isto é, o território sendo usado pelos agentes hegemonizados, que são constantemente forçados ao confinamento e à segregação territorial pelas forças de comando hegemônicas pautadas no uso corporativo do território e na negação de uso social.
\end{abstract}

Palavras-chave: Ocupações - Movimentos de Sem-teto - Cartografia da Ação - Maceió-AL.
We present a description of the vacant urban areas occupancy actions engendered by two homeless people movements that acted in the 2000s, in the city of Maceió, Alagoas. We propose the reading of the occupations through the means of Cartography of Action. This approach allows us to grasp at once the location of objects - vacant urban areas -; the actions directed by the homeless people - the occupations -; and the spontaneous and forced displacement of this population by reallocation of families to housing estates implemented by public agencies of the city government and of the state government. Upon the record of the displacements, it is possible to trace cartography of the action, that is, the territory being used by agents that are constantly forced to confinement and territorial segregation by the hegemonic command of forces grounded on corporate use of the territory and on the denial of its social use.

Keywords: Occupations - Homeless Movements - Cartography of Action - Maceió-AL

\section{Introdução}

Este trabalho ${ }^{1}$ resulta de uma pesquisa de campo realizada entre os anos de 2008 e 2010 que teve como objetivo mapear as ações de ocupações do que denominamos, à época, de "vazios urbanos".

Para realização do levantamento, buscou-se uma aproximação junto às lideranças dos dois movimentos de luta pela moradia que atuavam na cidade

\footnotetext{
${ }^{1}$ Uma versão preliminar e resumida deste trabalho, intitulada Dinâmica imobiliária no contexto da luta pela moradia: registro de uma experiência em Maceió-AL a partir da cartografia da ação, foi submetida e apresentada no XVI Encontro Nacional da Anpur, inscrito no eixo temático Dinâmica imobiliária, habitação e regulação urbana, a ocorrer em Belo Horizonte, MG, em maio de 2015.
} 
de Maceió para reconstrução e registro da história recente das ocupações de vazios urbanos a partir dos relatos dos próprios movimentos ${ }^{2}$. Realizaram-se visitas às ocupações e visitas técnicas às respectivas Secretarias de Infraestrutura e Habitação dos governos do estado e do município, cujos técnicos lidavam diretamente com as ocupações, ora na mediação dos conflitos, ora na participação direta dos conflitos.

Neste trabalho, descrevemos, a partir dos relatos, a experiência conjunta dos dois movimentos de luta pela moradia que atuaram na cidade de Maceió no período entre 1999 e 2009. Discorremos sobre um processo em torno da apropriação pelos sem-teto de determinadas áreas da cidade, bem como as mediações institucionais para "resolução" dos conflitos através da implantação de conjuntos habitacionais para realocação das famílias.

Partiremos das formas de ação empreendidas por ambos os movimentos e que correspondem às ocupações de vazios urbanos. Em seguida, discorreremos sobre os deslocamentos dos sem-teto no território maceioense, usando como instrumento de registro e análise a cartografia da ação como proposta por Ribeiro et al. (2001).

A partir das mediações institucionais envolvendo as Secretarias de Habitação e Infraestrutura da prefeitura municipal e do governo do estado, discutiremos as ações de remoções das ocupações e a realocação dos sem-teto em conjuntos habitacionais populares localizados na periferia da cidade, em áreas marcadas pela precária infraestrutura e acesso a serviços urbanos.

Concluímos que a localização dos conjuntos habitacionais, as remoções e as realocações fizeram parte de um mesmo processo centrado na produção e renovação de materialidades e criação de áreas urbanas funcionais ao confinamento e à segregação dos pobres na cidade; portanto, da criação de formas sociais e espaciais que cristalizam velhas concepções de moradia pautadas na negação do direito à cidade e ao território.

\section{Considerações preliminares}

À época do levantamento, a noção de vazios urbanos, como objetos-alvo da luta pela moradia, nos pareceu a mais adequada. Todavia, atualmente, parece-nos que esta seja uma noção ainda não muito bem definida pelas ciências sociais para tratar da complexa questão que envolve

\footnotetext{
${ }^{2}$ As fontes das informações históricas são os próprios relatos das lideranças dos movimentos, mas também dos técnicos da prefeitura de Maceió e do governo do estado de Alagoas.
} 
a existência de um estoque de domicílios vagos e a relação dos próprios movimentos de moradia em torno do que se convencionou chamar de vazios urbanos.

Vazio urbano se refere, na linguagem corrente, à situação de vacância de determinada área da cidade, mas nem sempre esse termo define, com precisão, a natureza do objeto referido, isto é, ele acaba designando ao mesmo tempo coisas distintas: uma área não edificada (um terreno, área verde) ou um objeto técnico construído (um prédio vago) ${ }^{3}$.

A partir de 2000, o Instituto Brasileiro de Geografia e Estatística (IBGE), para fins de levantamento estatístico, incorporou em sua metodologia censitária a categoria "domicílios vagos" para designar as unidades domiciliares que se encontravam efetivamente desocupadas na data de referência do censo.

A Fundação João Pinheiro, referência no levantamento e estudos do déficit habitacional no Brasil, também utiliza a categoria "domicílios vagos" tendo em vista que sua principal base de dados são os censos realizados pelo IBGE. A categoria domicílios vagos, portanto, é uma categoria técnica, definida para operacionalização do levantamento de dados e não define com rigor a questão ou fenômeno dos chamados vazios urbanos.

A questão é que o número apresentado por estas instituições, apesar de essenciais, não contabilizam o número de terrenos vagos. Os terrenos vagos também contribuem para a especulação imobiliária e, principalmente, também são objetos de interesse de ocupação pelos sem-teto. De acordo com Santana (2006), são comumente tratados como vazios urbanos na definição de Borde (2003) e Clichevsky (2001), mas não são incorporados às estatísticas oficiais.

Apesar de a noção de vazio urbano - mediante a multiplicidade de coisas que esse termo se presta a definir - não nos permitir precisar com rigor a natureza do objeto que se busca tratar aqui, continuaremos a utilizar esta noção - com as ressalvas aqui levantadas - por entendermos que ele nos permite uma aproximação da problemática atual referente ao fenômeno das ocupações de terras e habitação potencialmente úteis à moradia.

Nesse sentido, utilizaremos o termo vazio urbano para designar aquelas áreas da cidade - edificadas ou não - que se encontram em um dado momento desocupadas, mas que servem, no entendimento dos movimentos de sem-te-

\footnotetext{
${ }_{3}^{3}$ Borde (2003, apud SANTANA, 2006, p. 32) define vazios urbanos como "terrenos localizados em áreas providas de infraestrutura que não realizam plenamente a sua função social e econômica". Clichevsky (2002, apud SANTANA, 2006, p. 32) define vazios urbanos como "vazios especulativos, vazios latentes ou potenciais". É preciso considerar, ainda, conforme Santana (2006, p. 14) que "vazios urbanos não são apenas terrenos que se encontram vazios, sem uso, mas também estruturas edificadas vazias, ociosas e/ou subutilizadas".
} 
to e na própria lógica capitalista, à criação artificial de escassez habitacional necessária à especulação imobiliária e maior rentabilidade dos agentes proprietários públicos e privados. Entendemos que o vazio urbano deve ser considerado como um objeto geográfico, instituído e instituidor de valores e significados distintos segundo os usos e as intencionalidades que sobre esse objeto recaem.

Outros dois termos que gostaríamos de definir como os empregamos neste trabalho e que têm a ver com as ações dos poderes judiciário e executivo (estadual e municipal) são os de remoções por reintegração de posse e remoções para realocação dos sem-teto. Estes termos se prestam ao entendimento de duas situações distintas apesar de se prestarem a um mesmo fim: a desapropriação dos vazios urbanos ocupados pelos sem-teto e a busca (intencional ou não) pela desarticulação dos movimentos.

As remoções por reintegração de posse referem-se às desapropriações ensejadas pelo poder judiciário após ação aberta pelo poder proprietário do imóvel contra os sem-teto. Já as remoções para realocação referem-se às ações dos poderes executivos. Essa prática, em nosso estudo, consiste em desapropriar os imóveis ocupados pelos sem-teto e realocar estes últimas em unidades habitacionais construídas pelo próprio poder público em áreas periféricas, pobres, cujas localizações nem sempre são as desejadas pelas famílias que participam do movimento.

\section{As ocupações de vazios urbanos pelos movimentos de luta pela moradia}

O estudo Déficit Habitacional no Brasil, realizado pela Fundação João Pinheiro (2005), a partir do censo do IBGE de 2000, apontou a existência estimada de 4.580 .147 de domicílios vagos nas áreas urbanas brasileiras em contraposição a um déficit habitacional estimado em 4.140.088 de domicí$\operatorname{lios}^{4}$. Os estudos da FJP são sistemáticos e rigorosos e buscam constantemente a atualização dos dados. Hoje, estima-se a existência de 4.656.978 domicílios vagos nas áreas urbanas brasileiras em contraposição a um déficit habitacional estimado em 5.885.527 de domicílios urbanos.

A Fundação João Pinheiro (BRASIL, 2005) registrou na cidade de Maceió, no ano de 2000, um déficit habitacional absoluto de 33.514 domicílios em contraposição à existência de 29.286 domicílios vagos na área urbana. Em 2010 houve uma diminuição significativa do déficit e do número de domicí-

\footnotetext{
${ }^{4}$ A FJP (BRASIL, 2005, p. 7) entende o déficit habitacional como "noção mais imediata e intuitiva de necessidade de construção de novas moradias para a solução de problemas sociais e específicos de habitação". Nesse sentido, os números absolutos apontados como déficit equivaleria ao número de incremento de estoque necessário para acabar com o déficit.
} 
lios vagos na cidade em relação à 2000. O déficit habitacional absoluto na área urbana diminuiu de 33.514 domicílios para 11.925 domicílios em 2010; e o número de domicílios vagos passou de 29.286 para 11.185 naquele ano (BRASIL, 2013).

Outro indicador apontado no estudo é o déficit por faixa de renda. Sabe-se que o déficit habitacional é maior na camada populacional de mais baixa renda e que os integrantes dos movimentos de sem-teto em sua maioria possuem renda inferior a 03 salários mínimos ou mesmo não possuem salário fixo: vivem de bicos e trabalhos mal remunerados. Em Maceió, no ano de 2000, foi estimado um déficit de 23.841 unidades habitacionais $(86,59 \%$ do total) nessa faixa de renda ${ }^{5}$. Em 2010 também houve uma significativa diminuição do déficit nessa faixa de renda, passando de 23.841 para 8.391 unidades habitacionais (BRASIL, 2013).

Todavia, o número de terrenos vagos localizados em áreas infraestruturadas e valorizadas não é computado nas estatísticas oficiais e, tampouco, considerado adequadamente pelas políticas públicas de habitação destinadas aos pobres.

De todo modo, os números do déficit habitacional no Brasil em contraposição ao número de domicílios vagos constituem um fundamento para a escolha pela ocupação desses chamados vazios urbanos ${ }^{6}$.

Entre 1999 e 2007, em torno de 2.126 famílias integrantes do Movimento Terra Trabalho e Liberdade (MTL) e da União Nacional de Luta por Moradia Popular (UNMP) - representada no estado pela União Nacional de Movimento de Moradia em Alagoas - (UMMAL) ocuparam vazios urbanos localizados em pontos distintos da cidade de Maceió. Registramos cinco ocupações de terrenos localizados em bairros periféricos e uma ocupação em um prédio vazio localizado no centro da cidade: a ocupação Chico Mendes (Figura 01).

O registro de ocupações de vazios urbanos em Maceió aponta para um padrão de ocupação que se verifica em outras cidades brasileiras e que leva em conta alguns fatores como:

1. Tipo de imóvel: as ocupações se dão sobre dois tipos principais de imóveis: terras ou prédios.

\footnotetext{
${ }^{5}$ Em abril de 2000, o salário mínimo era de R\$151,00. Ao final da década, em janeiro de 2010, o salário mínimo vale $\mathrm{R} \$ 510,00$.

${ }^{6}$ As ocupações de prédios e terrenos vagos em áreas bem servidas e valorizadas também possui um caráter simbólico: chamar a atenção para a situação de carência de moradia ao tempo em que há um estoque de terras e habitação que servem à especulação imobiliária. Em curto prazo e de forma imediata, o objetivo dos sem-teto é conseguir acesso à habitação. Mas a localização para eles também importa de modo que, em longo prazo, o objetivo é pressionar os poderes públicos para que regulem o preço da terra urbana, coíbam a especulação imobiliária, melhorem o acesso ao trabalho, permitam à coletivização da infraestrutura urbana já presente, etc. Daí as ocupações ocorrerem em áreas centrais e/ou valorizadas do ponto de vista econômico.
} 
2. Localização do imóvel ocioso na cidade: considerando-se o meio ambiente construído, as ocupações ocorrem em áreas centrais e/ou em áreas periféricas da cidade. Geralmente, as ocupações na periferia ocorrem sobre terras e as ocupações no centro ocorrem em prédios.

3. Propriedade do imóvel: os imóveis ocupados podem ser públicos ou privados. Se públicos, os terrenos localizados na periferia ou os prédios localizados no centro geralmente pertencem a algum órgão do governo municipal, estadual ou da União. Se privados, o terreno ou prédio pode pertencer a pessoas físicas ou jurídicas.

4. Situação tributária do imóvel: geralmente, os imóveis ocupados pelos sem-teto são aqueles ociosos e devedores de IPTU junto à prefeitura.

Esses fatores são considerados pelos movimentos de luta pela moradia no momento da decisão da ocupação, pois a combinação deles influi na disputa pelo imóvel e permeiam, a todo o tempo, o conflito. Não há uma regra para o desfecho da luta, mas o fato da ocupação se situar em um terreno ou prédio que está localizado no centro ou na periferia; pertencer ao poder público ou a iniciativa privada; todos esses fatores condicionam as ações dos agentes envolvidos no conflito mediante os valores e funções dos imóveis segundo suas localizações.

Em Maceió, apenas uma ocupação (Ocupação Chico Mendes) ocorreu em um prédio localizado no centro da cidade. O imóvel ocupado pertencia ao Instituto Nacional do Seguro Social (INSS) que havia sido desativado após a transferência da Previdência Social para outro edifício. As demais ocupações ocorreram em terrenos localizados em bairros periféricos (Figuras 02 a 05).

A ocupação do prédio do INSS foi emblemática, pois ela fez parte de uma mobilização mais ampla que ocorreu em 11 de abril de 2006, que consistiu na ocupação de edifícios abandonados da Previdência Social e do INSS ${ }^{7}$ localizados nas áreas centrais. Essa mobilização foi coordenada e articulada em várias capitais brasileiras pela União Nacional por Moradia Popular (UNMP) - com sede na cidade de São Paulo - e da qual a UMMAL faz parte.

Durante a década de 2000, registraram-se inúmeros conflitos territoriais envolvendo os movimentos de luta pela moradia, agentes do poder público e da justiça, proprietários dos imóveis e populações do entorno das ocupações. $\mathrm{O}$ acionamento de discursos e atos para deslegitimar as ocupações e para criminalizar os sem-teto foi uma constante. Como decorrência dos fatos, as ocu-

\footnotetext{
${ }^{7}$ O Governo Federal construiu nas décadas de 1990 e 2000, em várias capitais brasileiras, novas sedes para abrigar as atividades da previdência social. Os edifícios do INSS foram emblemáticos neste processo, tanto que grande parte das ocupações de imóveis vazios que ocorrem nas capitais brasileiras se dá em antigos prédios do Instituto.
} 
pações foram paulatinamente desfeitas através de remoções que envolveram basicamente dois tipos: (i) remoções por reintegração de posse; (ii) remoções para realocação das famílias em conjuntos habitacionais construídos pelo poder público.

\title{
Uma cartografia das remoções e dos deslocamentos
}

Os relatos das ocupações de imóveis ociosos pelos sem-teto e das ações de remoção das famílias pelo poder público nos permite esboçar, a partir do território, uma cartografia da ação como proposta por Ribeiro et al. (2001).

\begin{abstract}
A cartografia aqui sugerida é a da denúncia e também a que oriente a ação social, desvendando contextos e reconhecendo atos, ou melhor, cada ato (ALMEIDA, 1994). Uma cartografia que vise à valorização imaginativa dos lugares vividos, onde a vida escorre ou ganha força reflexiva e transformadora. Como carta, mapa, não aparece como instrumento isolado ou como bela ilustração de textos, exacerbando critérios estéticos; mas, sim, como ferramenta analítica como sustento da memória dos outros. Nesse sentido, propõe-se uma cartografia incompleta que se faz fazendo; uma cartografia da prática, que não seja apenas dos usos e das funções do espaço, mas, também, usável, tentativa e plástica, através da qual se manifeste a sincronia espaço-temporal produzida e produtora da ação (RIBEIRO et al., 2001, p. 43).
\end{abstract}

A cartografia da ação nos permite registrar não só a localização dos objetos em disputa - os imóveis ociosos - mas os sujeitos e o sentido das ações inscritas no território, isto é, o território sendo usado (SILVEIRA, 2009), ou o território praticado (RIBEIRO, 2013). O mapeamento da ação social fugaz e de curta duração no tempo e no espaço não pretende ignorar a estrutura e seu dinamismo, mas liga-la à vida imediata ${ }^{8}$,

[...] sem que, com essa decisão, ocorra o desconhecimento das referências estruturais abrangentes da ação social. Essa diretriz de método não significa o elogio irresponsável do cotidiano, reprodutor de tantos preconceitos e subordinação (HELLER, 1972), mas, sim, a valorização de contextos, lugares e narrativas (RIBEIRO et al., 2001, p. 37, grifos nossos)

Os relatos devem ser lidos a partir das localizações dos objetos e das ações, mas, também, dos deslocamentos espontâneos e compulsórios dos movimentos de luta pela moradia. Os deslocamentos são reveladores de pro-

\footnotetext{
8 "A atualização da história depende dos atos diariamente praticados" (RIBEIRO, et al., 2001, p. 37).
} 
jetos políticos que indicam quem pode e onde é possível estar/existir. Os acontecimentos que marcaram as lutas e os deslocamentos desencadeados nos permitem montar um quadro de referência dos usos possíveis e efetivos da cidade.

Na figura 06 registramos os deslocamentos das ocupações Chico Mendes, Nilda Ferreira e Zumbi. Em outubro e novembro de 2008 as ocupações Chico Mendes e Nilda Ferreira (respectivamente), organizadas pela UMMAL, foram removidas forçadamente após a justiça conceder reintegração de posse do prédio do INSS (Ocupação Chico Mendes) ${ }^{9}$ e do terreno pertencente à Universidade Federal de Alagoas (Ocupação Nilda Ferreira) ${ }^{10}$.

As famílias se deslocaram para a Ocupação Cidade de Lona e formaram uma única grande ocupação. Já a ocupação Zumbi, organizada pelo MTL, se deslocou, em 2007, para a ocupação Dandara, após descobrirem que o terreno que ocupavam - à época de domínio da Prefeitura Municipal de Maceió - havia sido vendido à construtora e imobiliária CIPESA para a construção de um Shopping Center.

A partir das ações de reintegração de posse e dos deslocamentos, o número de áreas ocupadas pelos movimentos de luta pela moradia diminuiu pela metade sem que o problema de habitação das famílias fosse resolvido. A pressão dos movimentos sobre a prefeitura e o governo do estado para resolução dos conflitos gerados pelas ocupações resultou numa paulatina aproximação entre os sem-teto e os agentes das secretarias públicas de habitação do município e do estado.

Embora haja uma relativa autonomia dos movimentos sociais em relação ao Estado, esses não recusam a possibilidade de uma negociação (JACOBI, 1993, p. 154), de modo que "não pode ser desconsiderado o fator negociação na relação entre movimentos e Estado" (BOSCHI; VALADARES, 1983 apud JACOBI, 1993, p. 17). Nesse sentido, como afirma Ribeiro (2009, p. 154), é possível ocorrer mudanças nas motivações e nos objetivos da ação social a partir da mediação de instituições e de corriqueiras alianças políticas.

A aproximação das lideranças dos movimentos e dos gestores públicos ocorreu mediante o compartilhamento de atribuições institucionais entre município e estado referentes ao atendimento das demandas dos sem-teto. Nesse sentido, as lideranças do MTL se articularam com a Secretaria de Estado da Infraestrutura (Seinfra) e as lideranças da UMMAL se articularam com a Secretaria de Habitação Popular e Saneamento (SMHPS).

\footnotetext{
${ }^{9}$ Em 2006, a Secretaria Municipal de Habitação e Saneamento de Maceió (SMHPS) cadastrou as famílias da ocupação Chico Mendes para inseri-las em um programa de habitação de interesse social.

${ }^{10}$ Nesse processo de despejo, metade da ocupação se desfez.
} 
Quadro 1: Instituições mediadoras dos Movimentos MTL e UMMAL

\begin{tabular}{cccc}
\hline Ocupações & $\begin{array}{c}\text { Movimentos } \\
\text { Organizados }\end{array}$ & $\begin{array}{c}\text { Instituições } \\
\text { Mediadoras }\end{array}$ & $\begin{array}{c}\text { Esfera de } \\
\text { Governo }\end{array}$ \\
\hline $\begin{array}{c}\text { Paulo Bandeira } \\
\text { Zumbi }\end{array}$ & MTL & Seinfra & Estadual \\
Dandara & & & \\
\hline $\begin{array}{c}\text { Cidade de Lona } \\
\text { Chico Mendes }\end{array}$ & UMMAL & SMHPS & Municipal \\
Nilda Ferreira & & & \\
\hline
\end{tabular}

Fonte: Pesquisa de campo, 2009. Organizado pelo autor.

Essas articulações entre as lideranças dos movimentos e as secretarias de habitação foram estabelecidas para a negociação em torno da permanência/ remoção das famílias ocupantes dos imóveis. Os movimentos de sem-teto pleiteavam a desapropriação dos terrenos para cumprimento de sua função social e reivindicavam recursos para construção de moradias populares para as famílias ocupantes. Por outro lado, as instituições dos governos municipal e estadual mediavam os conflitos entre os movimentos sociais e um punhado de agentes que - mediante a valorização dos terrenos e das áreas ocupadas pelos sem-teto - exigia a remoção das ocupações.

\section{As articulações políticas entre os movimentos e o poder público}

A situação da propriedade do imóvel ocupado constitui um fator que influi na decisão prévia da ocupação pelos movimentos de luta pela moradia exatamente porque este fator implica na maior ou menor dificuldade concernente à desapropriação do imóvel e sua aquisição para exercício da função social. Parece-nos que há uma tendência e preferência pelas ocupações de imóveis públicos, embora esta não seja uma regra.

Os terrenos ocupados pelos movimentos MTL e UMMAL em Maceió pertenciam à Companhia de Recursos Humanos e Patrimoniais (CARHP) - órgão do governo do estado - e ao Sindicato dos Servidores Públicos de Maceió (Sindspref). Em 2000, este terreno foi cedido aos servidores públicos municipal pela ex-prefeita Kátia Born do Partido Socialista Brasileiro (PSB) (Figura 07).

O terreno ocupado pela UMMAL (ocupações Cidade de Lona, Chico Mendes e Nilda Ferreira) que pertencia a CARHP foi desapropriado pelo 
governo do estado para construção de moradias populares destinadas a uma comunidade de pescadores de um complexo de favelas situada às margens da Lagoa Mundaú, no bairro Vergel.

As famílias das três ocupações organizadas pela UMMAL que ocupavam o terreno tiveram que ser deslocadas pelo governo municipal, através da SMHPS, para outro conjunto habitacional. As famílias da Cidade de Lona - que ocupavam há 10 anos o terreno e já haviam constituído um sistema de relações econômicas e sociais com o entorno do bairro - foram obrigadas a se retirar do terreno que abrigaria a comunidade da Orla Lagunar e outras comunidades oriundas de ocupações espontâneas (Figura 03).

As famílias da ocupação Paulo Bandeira, que também ocupavam um terreno da CARHP no bairro Benedito Bentes, foram deslocadas pelo governo estadual, através da Seinfra, para um conjunto habitacional. Esse terreno ocupado estava situado próximo ao Shopping Center Pátio Maceió que foi construído em uma área $\left(34.800 \mathrm{~m}^{2}\right)$ que antes havia sido apropriada pela ocupação Zumbi (Figura 08 e Figura 09).

A construção do shopping valorizou os terrenos do entorno, inclusive aqueles ocupados pelo MTL. Mediante a pressão do mercado imobiliário para construção de habitações do Programa Minha Casa Minha Vida, destinadas às famílias com renda fixa, houve pressão para que o governo do estado removesse as ocupações Paulo Bandeira, Zumbi e Dandara. O governo do estado cedeu à pressão e removeu a ocupação Paulo Bandeira passando o terreno da CARHP para a iniciativa privada (Figura 10).

Após a resistência da ocupação Paulo Bandeira em sair do terreno, as famílias acabaram aceitando o acordo proposto pelo governo do estado e pela prefeitura municipal para construção de casas em outra área distante do centro comercial do bairro que ocupavam. Como se diz no jargão popular: "era pegar ou largar"!

Em situações de conflito e de disputa territorial são comuns negociações que tendem a um "consenso" que, nas palavras de Rancière, convida os atores sociais para “verificar que a solução 'mais razoável' é, na verdade, a única solução possível, a única autorizada pelos dados da situação tais como os conhecem os Estados e seus especialistas" (RANCIÈRE, 1996, p. 379-380).

Nesse sentido, tanto as ocupações da UMMAL como as ocupações do MTL sofreram remoções pela prefeitura municipal e pelo governo do estado no sentido de que estes priorizaram os interesses econômicos em detrimento dos interesses sociais no que concerne à destinação dos vazios urbanos ao exercício da função social da propriedade. 


\section{A implantação de conjuntos habitacionais para os pobres}

Para atendimento da demanda habitacional dos movimentos de luta pela moradia e de outras ocupações espontâneas da cidade, a prefeitura municipal e o governo do estado produziram novos conjuntos habitacionais populares. Sem receita própria para produção habitacional, as gestões públicas do município e do estado dependeram de repasses financeiros do Governo Federal provindos do Orçamento Geral da União (OGU) e do Fundo Nacional de Habitação de Interesse Social (FNHIS). A resolução 460/518 também foi um instrumento utilizado pelas gestões públicas para o provimento habitacional ${ }^{11}$.

Os repasses financeiros da União para o estado e para o município estiveram condicionados à oferta de terras em áreas infraestruturadas como contrapartida. $\mathrm{O}$ estado e o município, que diziam não possuir banco de terras, recorreram à compra de terrenos na periferia do bairro Benedito Bentes para poderem receber os repasses federais para construção das moradias populares.

Entre os anos 2000 e 2009 foram produzidas no município de Maceió - a partir da celebração de convênios entre o município, o estado e a União - em torno de 10.159 unidades habitacionais destinadas às ocupações dos movimentos de luta pela moradia e outras ocupações espontâneas espalhadas pela cidade (Quadros 02 e 03).

Quadro 02: Conjuntos habitacionais implantados pela prefeitura de Maceió (2000-2009)

\begin{tabular}{c|c|c}
\hline $\begin{array}{c}\text { Conjunto } \\
\text { habitacional }\end{array}$ & $\begin{array}{c}\mathbf{N}^{\mathbf{0}} \text { de unidades } \\
\text { Habitacionais }\end{array}$ & $\begin{array}{c}\text { Bairros de } \\
\text { implantação }\end{array}$ \\
\hline Selma Bandeira & 335 & Benedito Bentes \\
Carminha/Freitas Neto & 2.400 & Benedito Bentes \\
Denisson Menezes & 682 & Cidade Universitária \\
$1^{\text {o de junho }}$ & 200 & Benedito Bentes \\
Carminha 01 & 1.003 & Benedito Bentes \\
Freitas Neto & 741 & Benedito Bentes \\
Cidade Sorriso I & 1.542 & Benedito Bentes \\
Cidade Sorriso II & 1.046 & Benedito Bentes \\
Vila dos pescadores I e II & 450 & Trapiche da Barra \\
\hline
\end{tabular}

\section{Total}

8.399

Fonte: Secretaria Municipal de Habitação e Saneamento. Organizado pelo autor.

${ }^{11}$ A Resolução 460/518 instituiu o Programa Operações Coletivas. Este Programa objetivou atender às demandas habitacionais das famílias de baixa renda, com financiamento direto à pessoa física, organizada de forma coletiva, em parceria com entidade organizadora, através do financiamento com recursos do Fundo de Garantia por Tempo de Serviço (FGTS). 
Quadro 03: Conjuntos habitacionais implantados pelo governo do estado (2000-2009)

\begin{tabular}{c|c|c}
\hline $\begin{array}{c}\text { Conjunto } \\
\text { habitacional }\end{array}$ & $\begin{array}{c}\mathbf{N}^{\mathbf{0}} \text { de unidades } \\
\text { Habitacionais }\end{array}$ & $\begin{array}{c}\text { Bairros de } \\
\text { implantação }\end{array}$ \\
\hline Paulo Bandeira & 780 & Benedito Bentes \\
Vila São Pedro & 150 & Vergel do Lago \\
Santa Maria & 821 & Cidade Universitária \\
\hline Total & $\mathbf{1 . 7 6 0}$ &
\end{tabular}

Fonte: Secretaria de Infraestrutura do Estado de Alagoas (Seinfra). Organizado pelo autor.

A maioria dos conjuntos foi implantada na periferia da cidade, no bairro Benedito Bentes, distante das áreas centrais e da própria centralidade do bairro (Figura 11). Este bairro surgiu em 1986, com a implantação de um conjunto habitacional para população de baixa renda. $\mathrm{O}$ crescimento do bairro e o adensamento populacional contribuíram para o espraiamento da cidade e, atualmente, estima-se uma população que lá vive de 220 mil habitantes. Grande parte dos moradores é constituída por trabalhadores pobres que se deslocam diariamente para trabalhar nas áreas mais ricas da cidade.

Historicamente, o bairro Benedito Bentes acolhe as implantações das habitações populares produzidas pelos governos municipal e estadual e se constitui, assim, em um lugar de residência da população pobre trabalhadora ou daqueles que não tem onde morar e ocupam as áreas "irregularmente". Apesar da densidade populacional, parte do bairro constitui um espaço rarefeito e opaco (SANTOS; SILVEIRA, 2005) do ponto de vista da infraestrutura e serviços urbanos, marcado pela escassez material. Ao observarmos a figura 11, vemos as áreas da cidade mais densas a partir do traçado das vias em contraposição às áreas rarefeitas onde estão implantados os conjuntos habitacionais.

\section{Uma cartografia da realocação dos movimentos para conjuntos habitacionais}

A partir de 2009, após negociações e acordos com as lideranças dos movimentos, intensificou-se o processo de realocação das ocupações do MTL e da UMMAL para os conjuntos habitacionais implantados na periferia da cidade pela prefeitura municipal e pelo governo do estado. Os conjuntos implantados serviram para uma série de remoções de ocupações "irregulares", dentre estas, ocupações de movimentos de luta pela moradia e ocupações espontâneas que chamamos de favelas ou comunidades (Figuras 12 a 15). 
A partir das localizações das ocupações e das localizações dos conjuntos habitacionais implantados, buscamos elaborar uma cartografia dos deslocamentos das ocupações para os conjuntos. A série de deslocamentos, vista a partir do território usado pelo Estado, vai revelando uma história da criação de lugares para "confinamento" da população pobre. Esses deslocamentos, apesar de pactuados, são um demonstrativo de como o espaço é pensado e racionalizado a partir das práticas de dominação criadoras de uma cidade fragmentada, segregada e confinada (Figura 16).

A seguir, descrevemos os deslocamentos das ocupações a partir da figura 16:

1. Maio de 2009: a ocupação Cidade de Lona, organizada pela UMMAL, foi realocada para o Conjunto Cidade Sorriso 01 pela Secretaria Municipal de Habitação e Saneamento do Município de Maceió (SMHPS).

2. Maio de 2009: a ocupação espontânea River Plate foi realocada para o conjunto Cidade Sorriso 01 pela SMHPS.

3. Maio de 2009: a ocupação espontânea Canaã foi realocada para o conjunto Cidade Sorriso 01 pela SMHPS.

4. Maio de 2009: a ocupação espontânea do complexo de favelas da orla lagunar foi realocada para o conjunto Cidade Sorriso 01 pela SMHPS.

5. Julho de 2009: outra parte da ocupação espontânea do complexo de favelas da orla lagunar foi realocada para o conjunto Vila São Pedro pela Secretaria de Infraestrutura do Estado (Seinfra).

6. Outubro de 2009: a ocupação Paulo Bandeira, organizada pelo MTL, foi realocada para o Conjunto de mesmo nome - Paulo Bandeira pela Seinfra.

7. Outubro de 2009: a ocupação espontânea Grota da Alegria foi realocada para o conjunto Paulo Bandeira pela Seinfra.

8. 2009: estava em andamento a remoção da ocupação Chico Mendes, organizada pela UMMAL, para o conjunto Cidade Sorriso 02 implantado pela SMHPS.

9. 2009: estava em andamento a remoção da ocupação Nilda Ferreira, organizada pela UMMAL, para o conjunto Cidade Sorriso 02 implantado pela SMHPS.

10.2009: estava em andamento a remoção da terceira parte dos moradores do complexo de favelas da orla lagunar para o conjunto Santa Maria implantado pela Seinfra. 
O ano de 2009 foi um ano de inúmeros e intensos deslocamentos de ocupações para os novos conjuntos habitacionais construídos pela prefeitura e pelo governo do estado após uma década de luta. O Benedito Bentes segue sendo um bairro prioritário para a implantação de moradias populares destinadas à população pobre que não tem como arcar com os custos da habitação e que depende diretamente da oferta de casas pelos poderes públicos.

Até 2010, das 2.126 famílias que compunham os movimentos MTL e UMMAL, apenas 1.136 famílias haviam sido realocadas para os conjuntos habitacionais, isto é, apenas $53,43 \%$ dos sem-teto que participaram dos movimentos de luta pela moradia. Mediante os acirrados conflitos vivenciados pelos movimentos sociais, muitas famílias abandonam o movimento e se dispersam pela cidade na busca pela sobrevivência cotidiana.

Ao mesmo tempo, diante das limitações orçamentárias e dos embates políticos e econômicos, as gestões públicas se deparam com dificuldades para atender à demanda habitacional dos movimentos organizados, mas também das ocupações espontâneas irregulares.

\section{Considerações finais}

O monopólio da informação e da representação cartográfica dos diversos elementos estratégicos do território - vivos e não vivos (LATOUR, 2012) - é domínio do Estado e dos demais agentes hegemônicos.

A informação sobre o fenômeno das ocupações pelos sem-teto e das preferências por determinados vazios urbanos já é largamente difundida e conhecida por aqueles que temem as ocupações de suas propriedades. Não seria por isso que junto ao fenômeno das ocupações assistimos outro que é o do cercamento e construção de muros para impedir o acesso aos vazios urbanos, como mostram as figuras 02 e 10 ?

Enquanto os agentes hegemônicos possuem o "domínio" e "controle" territorial, e lançam mão das mais variadas estratégias para manutenção deste controle, os agentes hegemonizados usam o território a partir das táticas, isto é, do aproveitamento "das falhas que as conjunturas particulares vão abrindo na vigilância do poder proprietário" (CERTEAU, 1994, p. 100-101) 12 e, nesse

\footnotetext{
12 “[...] chamo de tática a ação calculada que é determinada pela ausência de um próprio. Então nenhuma delimitação de fora lhe fornece a condição de autonomia. A tática não tem por lugar senão o do outro. E por isso deve jogar com o terreno que lhe é imposto tal como o organiza a lei de uma força estranha [...] Ela opera golpe por golpe, lance por lance. Aproveita "ocasiões" e delas depende, sem base para estocar benefícios, aumentar a propriedade e prever saídas [...] Tem que utilizar, vigilante, as falhas que as conjunturas particulares vão abrindo na vigilância do poder proprietário" (CERTEAU, 1994, p. 100-101).
} 
sentido, "constroem lugares no âmago do espaço-temporalidade dominante" (RIBEIRO, et al., 2001, p. 42).

A cartografia que aqui apresentamos busca revelar esses outros usos do território - a partir dos hegemonizados - e não somente dos hegemônicos. Apesar da adesão dos sujeitos aos movimentos não ser sempre permanente dependente das conquistas imediatas - o problema da habitação o é e, desse modo, outros agentes vão sendo incorporados à luta, novas táticas vão sendo delineadas e executadas.

No âmbito nacional, a década de 2000 foi marcada por alguns avanços jurídicos e institucionais no campo da aclamada reforma urbana, cujo eixo central pauta-se na luta pelo direito à cidade. A criação do Ministério das Cidades em 2003, a regulação dos artigos 182 e 183 da Constituição Federal de 1988 a partir do Estatuto da Cidade (Lei $\left.n^{\circ} 10.258 / 2001\right)$ foram marcos importantes resultantes da luta histórica dos movimentos sociais urbanos.

Todavia, se, por um lado, o reconhecimento jurídico do direito à cidade (geral) e do direito à moradia (particular) foi conquistado a partir de discursos, arranjos institucionais, planos diretores, legislações, etc., por outro, o uso efetivo do território não o foi. Isto é, a aplicação dos instrumentos legais - no nível local - que garantissem a função social da propriedade e o direito a uma cidade integrada e não fragmentada, a partir da permanência de pobres em determinadas áreas ligadas aos inúmeros subsistemas de infraestrutura e serviços urbanos, não se refletiu concretamente nas ações dos poderes públicos locais.

As ocupações de imóveis ociosos pelos movimentos de luta pela moradia representam, em última análise, a continuação da luta pela aplicação e efetivação dos direitos juridicamente reconhecidos. No entanto, o que buscamos demonstrar neste trabalho, a partir do relato das experiências de ocupações e remoções, foi justamente a ação contrária do poder público no que concerne à formulação de uma política de habitação que contemplasse os desígnios dos sem-teto em permanecer nas áreas ocupadas.

A cartografia da ação aqui esboçada buscou revelar, a partir das experiências registradas, o uso efetivo do território maceioense no contexto das contradições subjacentes entre o discurso e a prática, a lei e o direito, o interesse público e o interesse privado.

A implantação dos conjuntos habitacionais pela prefeitura do município e pelo governo do estado apontou para as práticas tradicionais de confinamento e segregação dos pobres. Em outras palavras, a ação do poder público resultou na produção de novas materialidades e na cristalização de um tempo no espaço que redefiniram a vida das famílias e que, no devir, trará consequências para o conjunto de relações que se tecem na cidade. 
Como afirma Ribeiro (2000, p. 240) "existem atos a serem reconhecidos e valorizados e, ainda, vozes a serem ouvidas e inscritas na formulação dos futuros possíveis".

\section{Figuras}

Figura 01. Localizações das ocupações de imóveis ociosos pelos Movimentos MTL e UMMAL em Maceió, Alagoas (1999-2007)

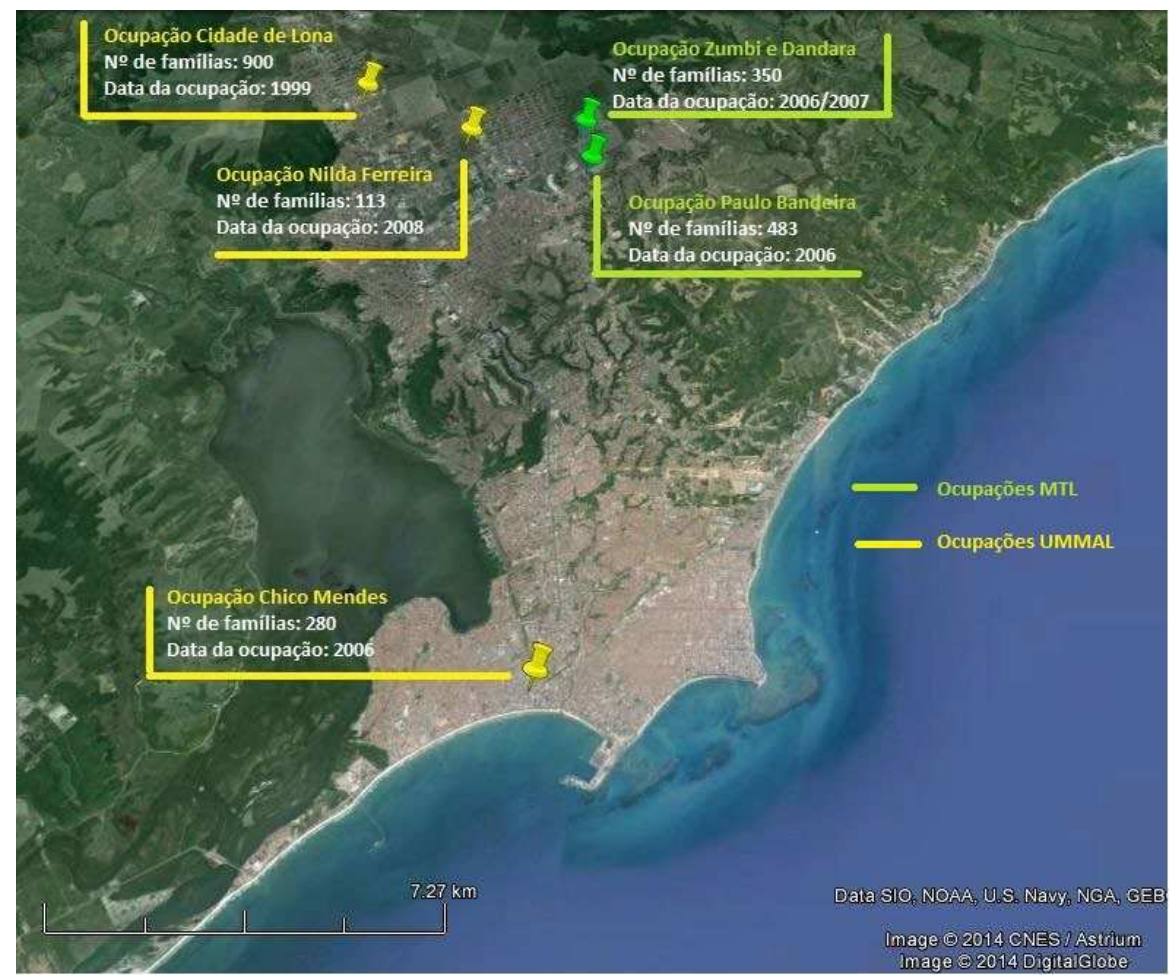

Fonte: Google Earth. Elaborado pelo autor a partir de pesquisa de campo realizada em 2009. 
NOBRE, Carlos Eduardo. Cartografia da ação: ocupações de vazios urbanos pelos movimentos de sem-teto...

Figuras 02 e 03. Prédio do INSS onde ocorreu a ocupação Chico Mendes (direita) e Ocupação Cidade de Lona (esquerda)

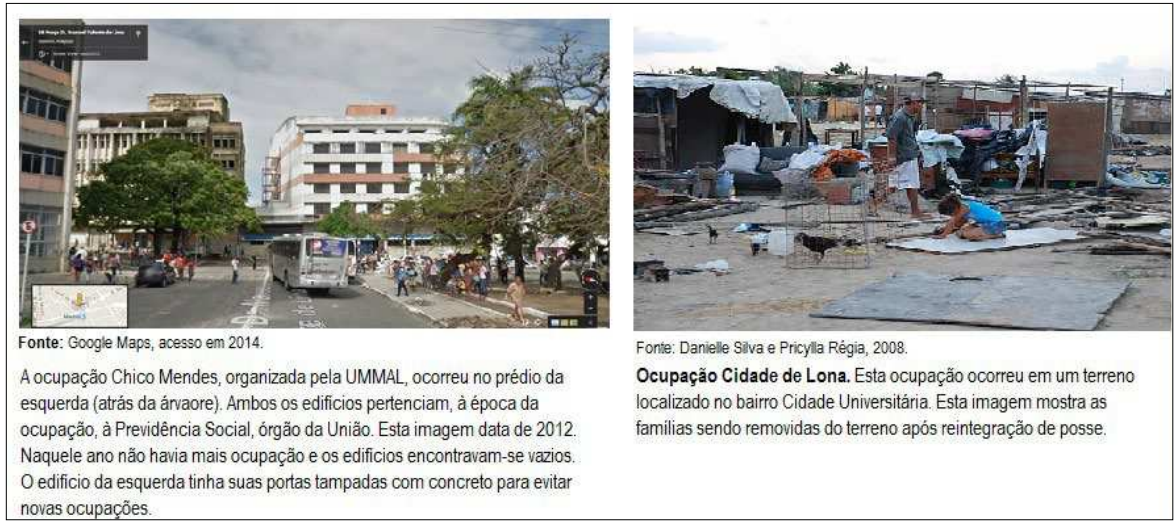

Figuras 04 e 05. Ocupações Paulo Bandeira (direita), Dandara e Zumbi (esquerda)

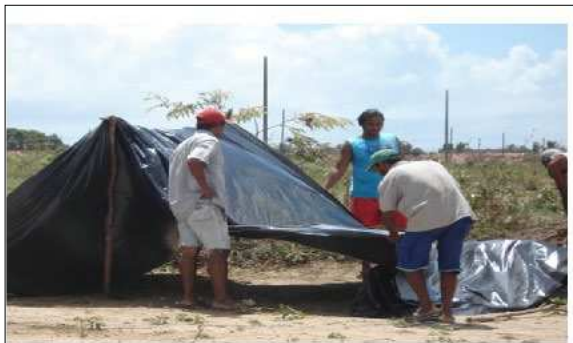

Fonte: Desconhecida

Ocupação Paulo Bandeira. A ocupação ocorreu em um terreno no bairro Benedito Bentes. Integrantes do MTL iniciam o trabalho de montagem das barracas de lona que serviram inicialmente como abrigo às familias de sem-teto. Com o tempo, os abrigos de lona foram substituidos por casas de barro e de taipa.

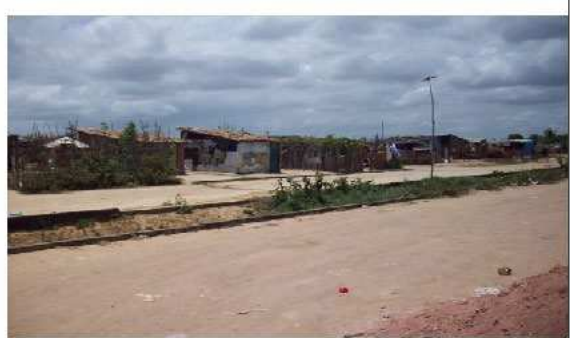

Fonte: Pesquisa de campo, 2009

Ocupações Dandara e Zumbi. Estas ocupações também ocorreram em um terreno localizado no bairro Benedito Bentes. Nesta imagem vemos casas de taipa, com cercas em torno das casas e plantação de hortas comunitárias. 
Figura 06. Deslocamento das ocupações após reintegração de posse em 2008

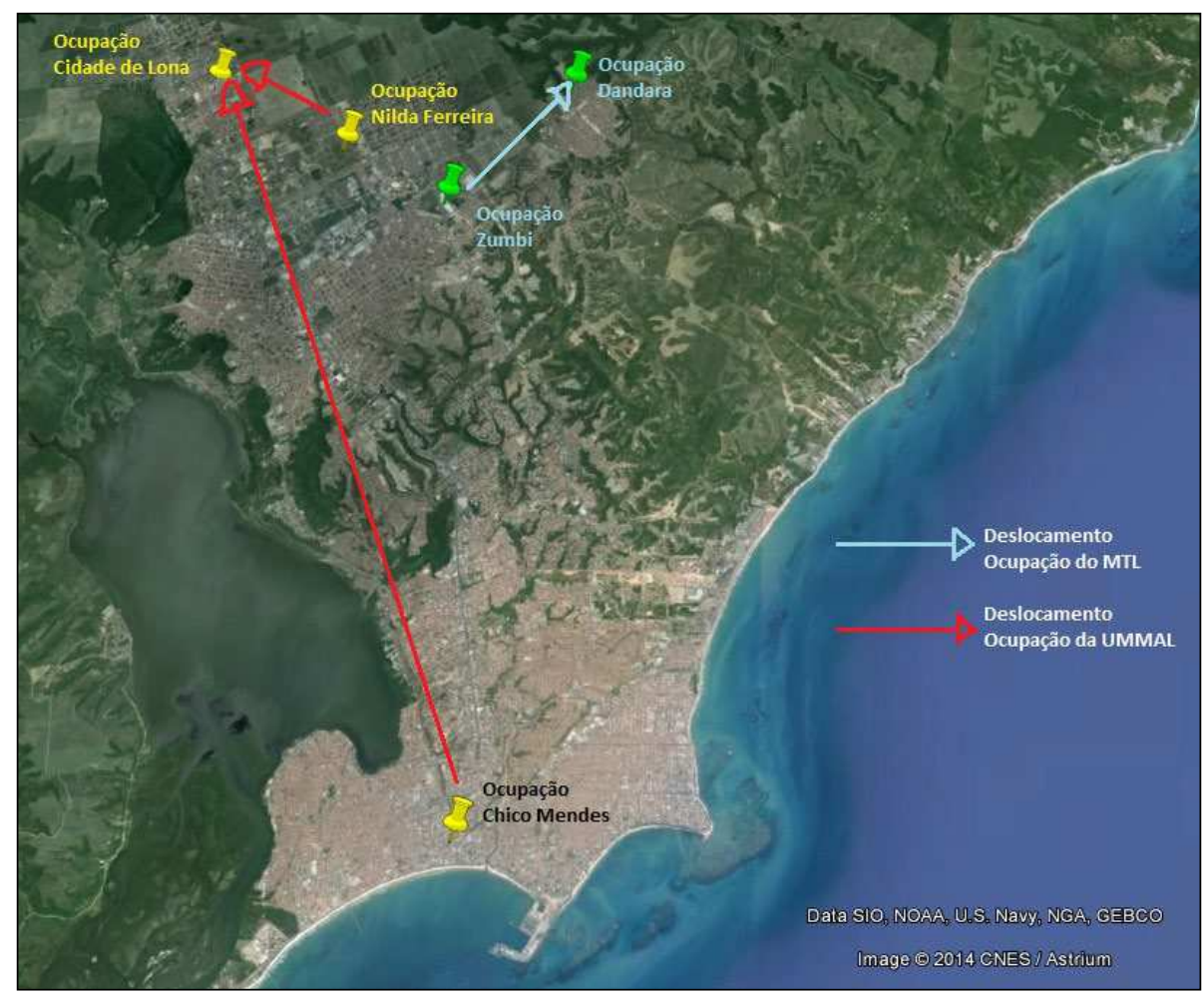

Fonte: Google Earth. Elaborado pelo autor a partir de pesquisa de campo realizada em 2009. 
NOBRE, Carlos Eduardo. Cartografia da ação: ocupações de vazios urbanos pelos movimentos de sem-teto...

Figura 07. Propriedade dos imóveis ocupados pelos movimentos MTL e UMMAL

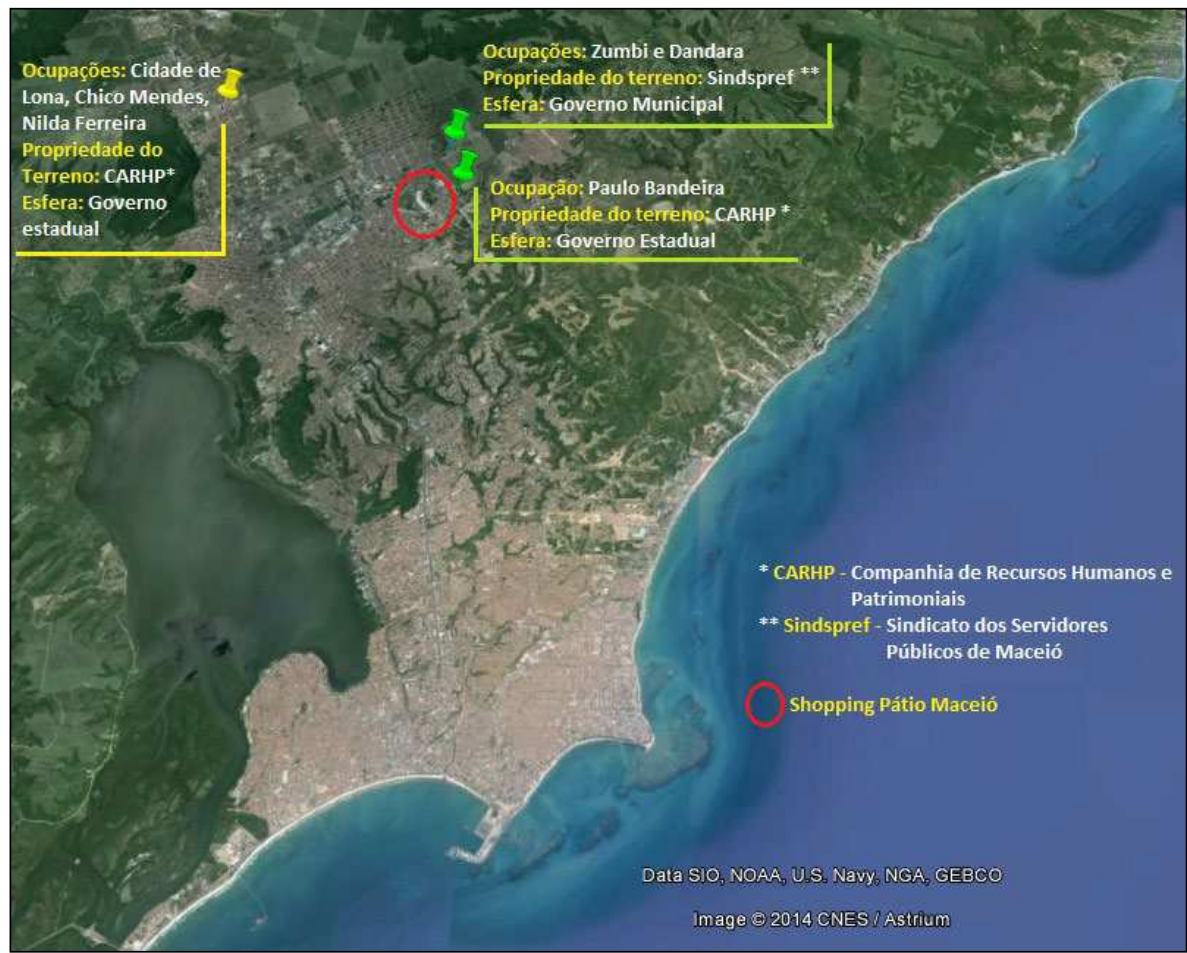

Fonte: Google Earth. Elaborado pelo autor a partir de pesquisa de campo realizada em 2009. 
Figura 08. Proximidade entre o shopping Pátio Maceió e a ocupação Paulo Bandeira

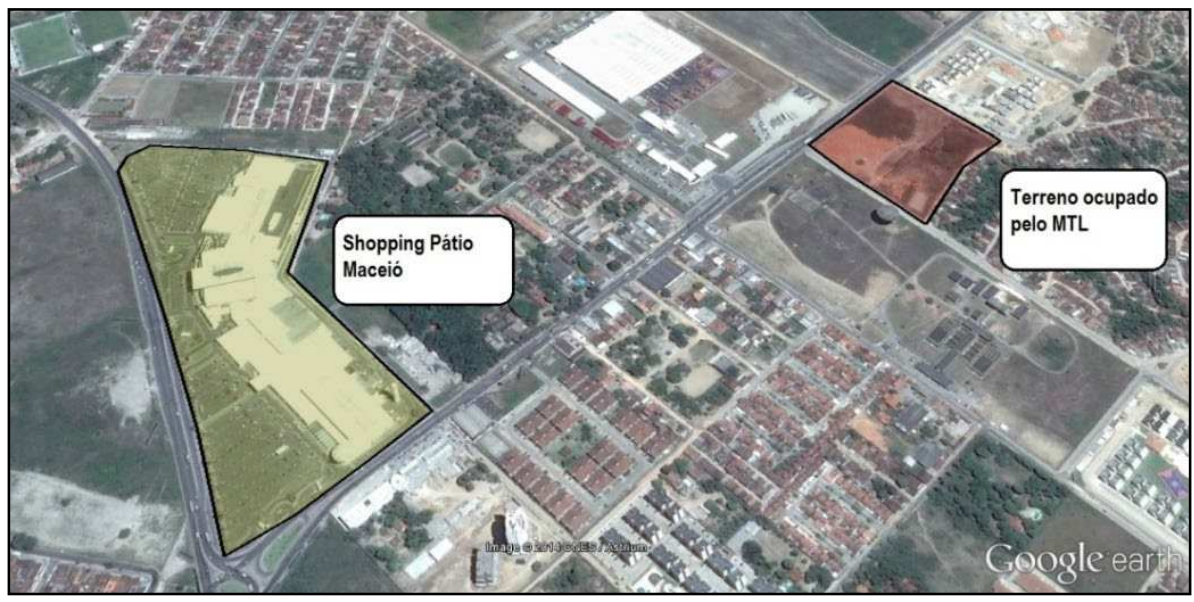

Fonte: Google Earth, 2014. Elaborado pelo autor.

Figura 09. Shopping Pátio Maceió

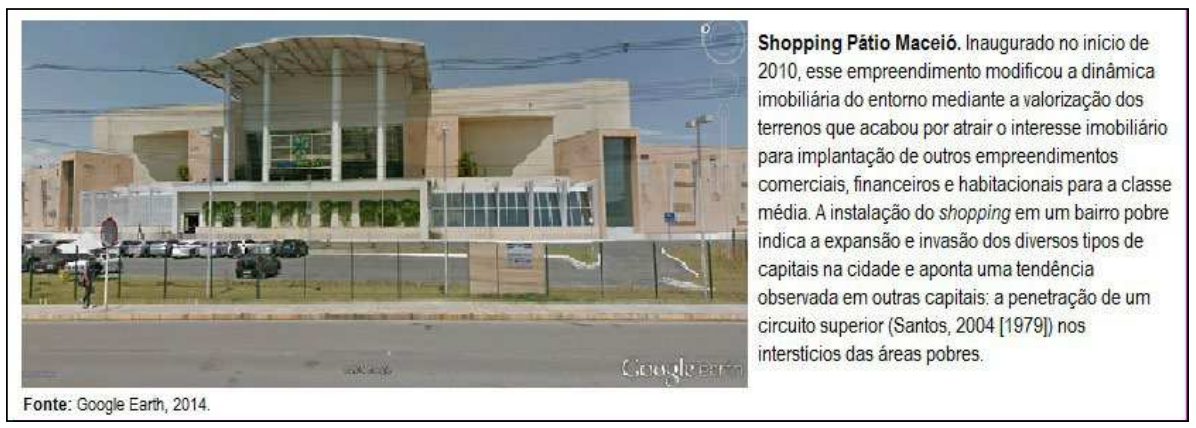


NOBRE, Carlos Eduardo. Cartografia da ação: ocupações de vazios urbanos pelos movimentos de sem-teto...

Figura 10. Terreno da CARHP onde ocorreu a ocupação Paulo Bandeira

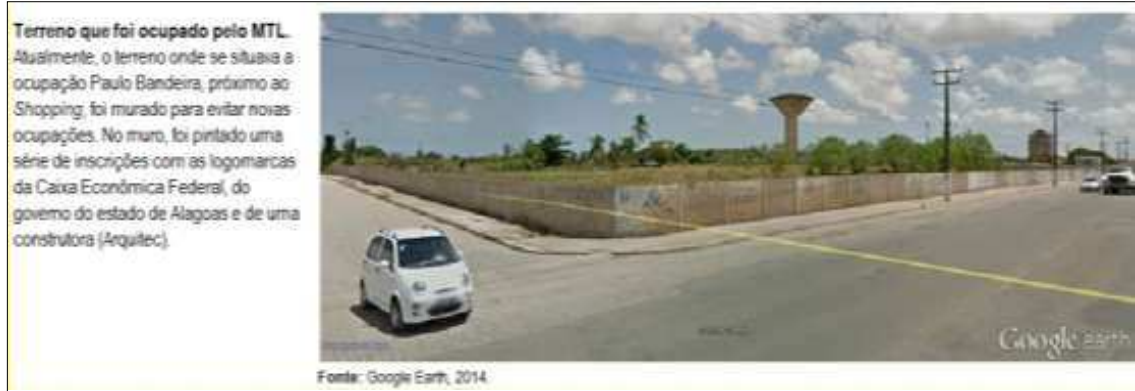

Figura 11. Conjuntos habitacionais implantados pela prefeitura de Maceió (SMHPS) e pelo governo do estado de Alagoas (Seinfra) entre 2000-2009

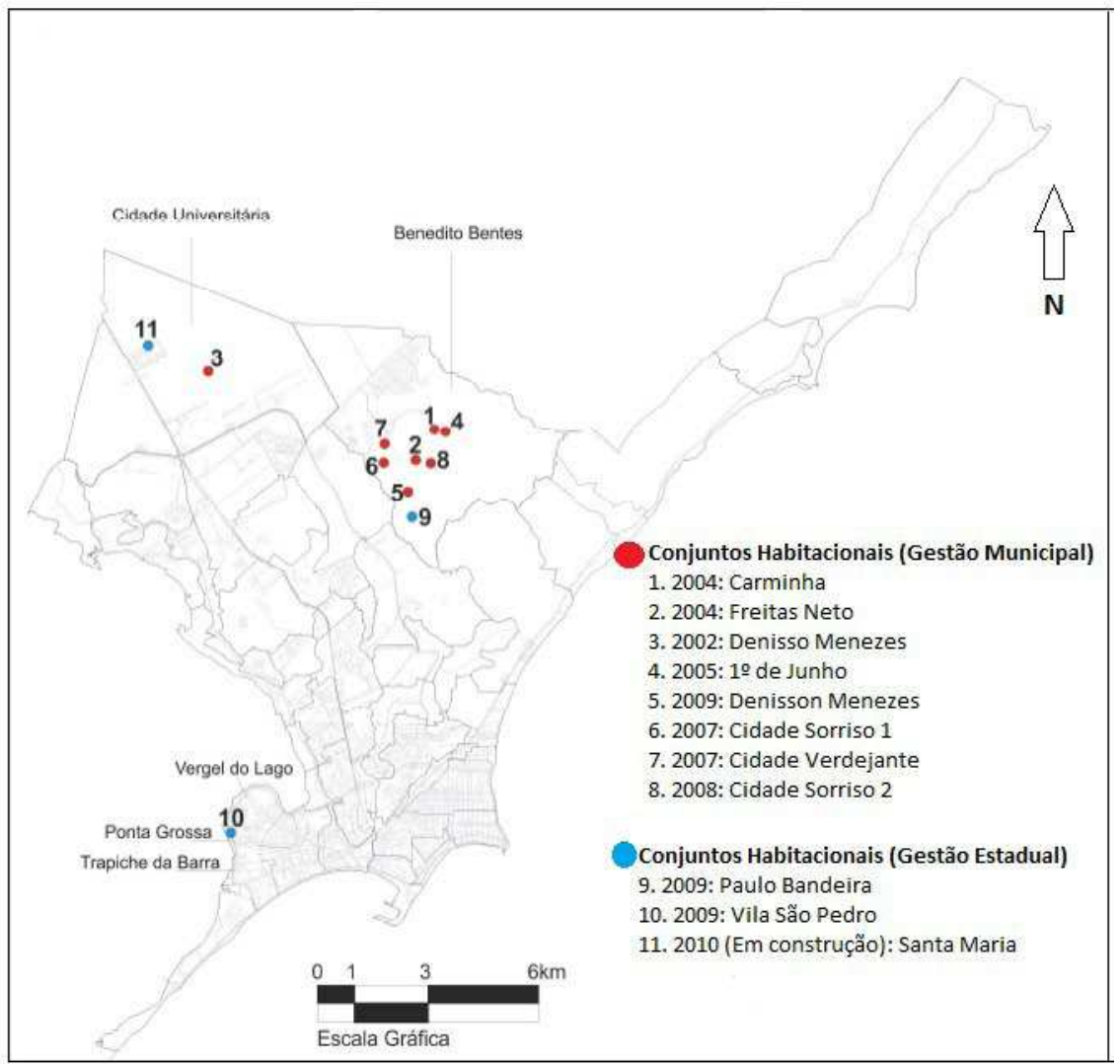

Fontes: Secretaria Municipal de Habitação e Saneamento (SMHPS); Secretaria de Infraestrutura do Estado de Alagoas (Seinfra). Elaboração cartográfica: Andréia Lopes Muniz Corrêa e Carlos Eduardo Nobre. 
Figuras 12 e 13. Conjuntos habitacionais implantados pela SHMPS: Cidade Sorriso 01 (esquerda) e Cidade Sorriso 02 (direita)

\begin{tabular}{|l|l|}
\hline & \\
\hline $\begin{array}{l}\text { Fonte: Pesquisa de campo, 2009. } \\
\text { Cidade Sorriso 01. O conjunto habitacional localizou-se em uma área } \\
\text { carente de infraestrutura e serviços urbanos (transporte, escola, posto de } \\
\text { saúde). Foram construidas 1.542 unidades habitacionais com recursos } \\
\text { do governo federal. Parte das moradias foi destinada às ocupações } \\
\text { Cidade de Lona e Chico Mendes (UMMAL). }\end{array}$ & $\begin{array}{l}\text { Cidade Sorriso 02. A localização deste empreendimento, assim } \\
\text { como os demais, marca a periferização da pobreza, do espraiamento } \\
\text { da cidade e do custo público com a extensão futura de infraestrutura e } \\
\text { serviços urbanos. A falta de pavimentação demonstra a pouca } \\
\text { densidade urbana assemelhando-se a uma área rural. }\end{array}$ \\
\hline
\end{tabular}

Figuras 14 e 15. Conjuntos habitacionais implantados pela Seinfra: Paulo Bandeira (direita) e Santa Maria (esquerda)

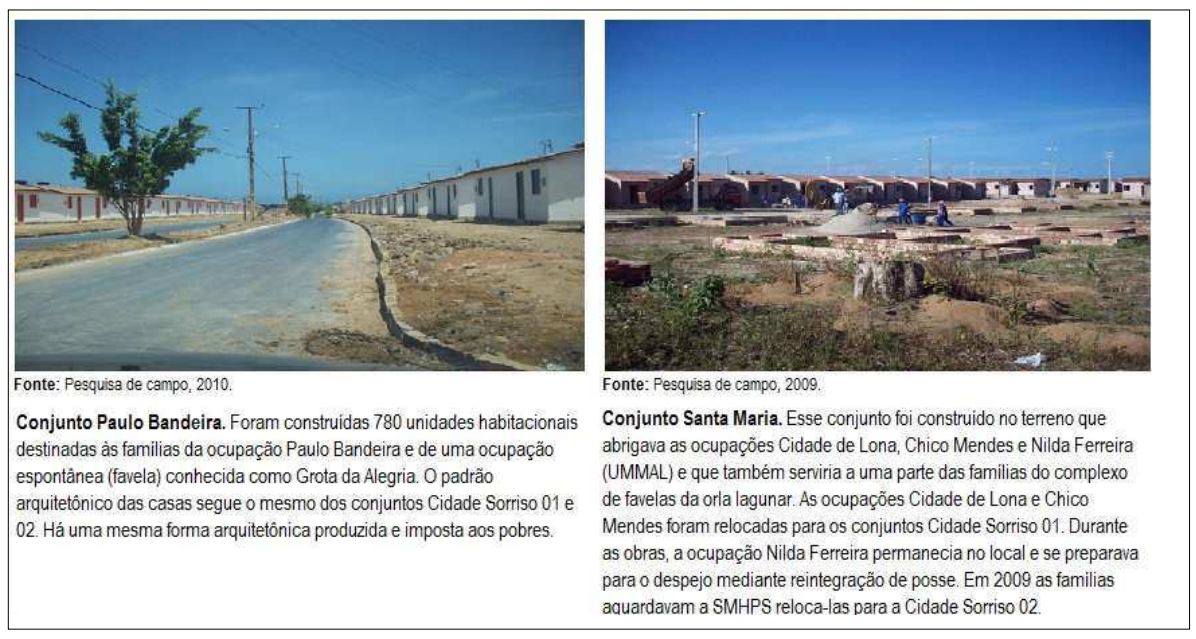


Figura 16. Realocações das ocupações do MTL, da UMMAL e das ocupações espontâneas para conjuntos habitacionais implantados pela prefeitura de Maceió e pelo Governo do Estado de Alagoas, 2009

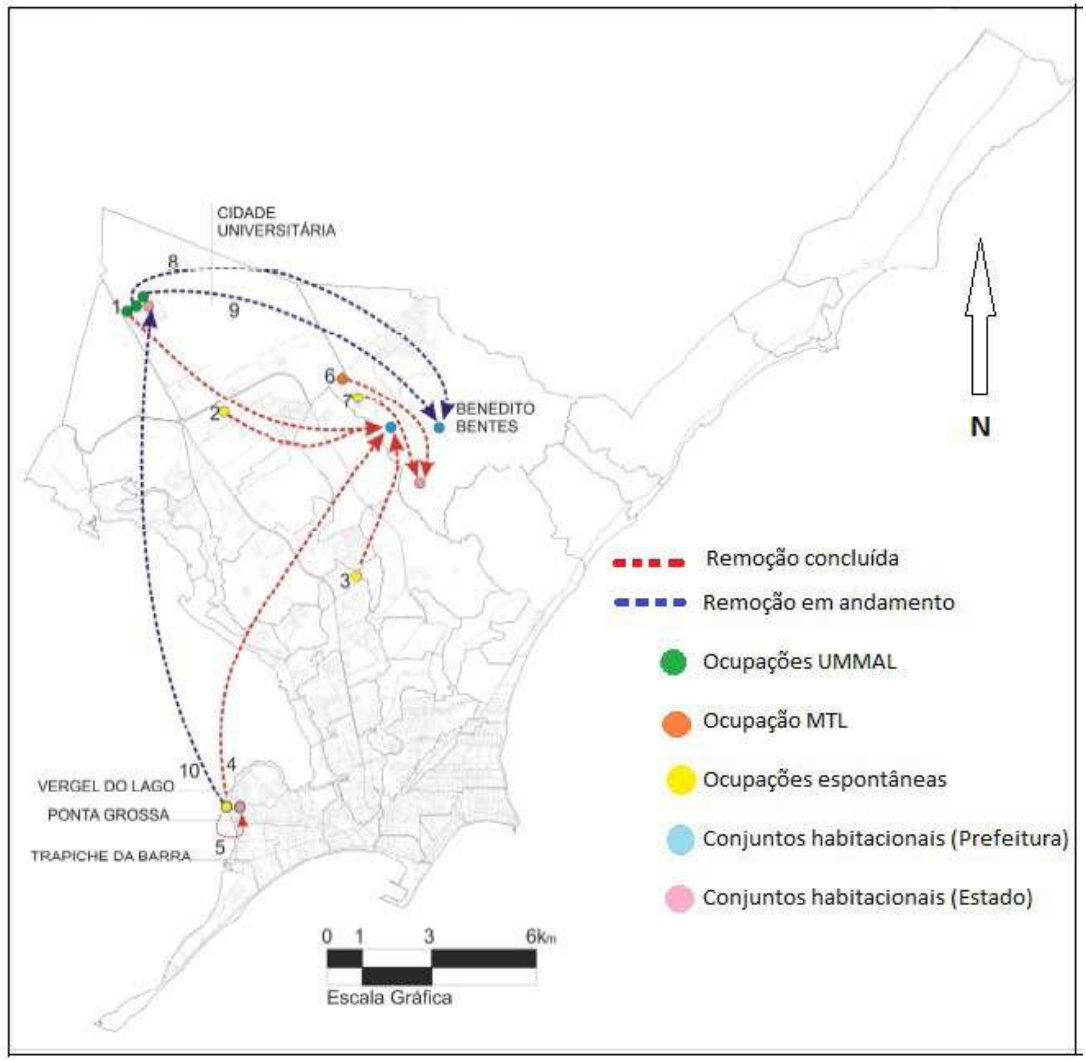

Fonte: Pesquisa de campo, 2009. Elaboração cartográfica: Andréia Lopes Muniz Corrêa e Carlos Eduardo Nobre. In Nobre (2010).

\section{Referências}

ALMEIDA, Alfredo W. B. Carajás: a guerra dos mapas. Belém: Falangola, 1994.

BORDE, Andréa de L. Pessoa. Percorrendo os vazios urbanos. In: SIMPÓSIO PERSPECTIVAS DAS FORMAS URBANÍSTICAS NO SÉCULO XXI, 2003, Florianópolis. Cadernos de resumos... Florianópolis, 2003.

BOSHI, Renato.; VALADARES, Lícia do P. Problemas teóricos na análise de movimentos sociais: comunidade, ação coletiva e o papel do Estado. Espaço \& Debates, São Paulo, NERU, 1983. 
BRASIL. Lei n. 10.257, de 10 de julho de 2001. Regulamenta os arts. 182 e 183 da Constituição Federal, estabelece diretrizes gerais da política urbana e dá outras providências. Diário Oficial da União, Presidência da República, Brasília, DF, 11 de julho de 2001.

BRASIL (Ministério das Cidades/Secretaria Nacional de Habitação). Déficit habitacional no Brasil - 2005. 2 ed. Belo Horizonte: Fundação João Pinheiro, 2005.

BRASIL. Constituição, (1988). Constituição da República Federativa do Brasil. Texto Constitucional de 1988. 28 ed. Brasília, DF, Câmara dos Deputados, Coordenação de Publicações, 2007.

BRASIL (Ministério das Cidades/Secretaria Nacional de Habitação). Déficit habitacional no Brasil - 2010. Belo Horizonte: Fundação João Pinheiro, 2013.

CERTEAU, Michel de. A invenção do cotidiano: 1. artes de fazer. Petrópolis, RJ: Vozes, 1994. $352 \mathrm{p}$.

CLICHEVSKY, Nora (Org.). Tierra vacante en ciudades latinoamericanas. Canadá: Lincoln Institute, 2001. $160 \mathrm{p}$.

HELLER, Agnes. O cotidiano e a história. In: POUILLON, Jean (Org.). Problemas do estruturalismo. Rio de Janeiro: Zahar Editores, 1968.

JACOBI, Pedro. Movimentos sociais e políticas públicas - demandas por saneamento básico e saúde. São Paulo. 2 ed. Cortez, 1993. 166 p.

LATOUR, Bruno. Reagregando o social. Salvador: Edufba, 2012; Bauru, São Paulo: Edusc, 2012. $400 \mathrm{p}$.

RANCIÈRE, Jacques. O dissenso. In: NOVAES, A. A Crise da Razão. Companhia das Letras, 1996, p. 367-382.

RIBEIRO, Ana Clara T. Faces ativas do urbano: mutações num contexto de imobilismo. In: RIBEIRO, Ana Clara T. (Comp.) Repensando a experiência urbana da América Lati$n a$ : questões, conceitos e valores. Buenos Aires: Clacso, 2000, p. 235-250. Disponível em: http://168.96.200.17/ar/libros/urbano/urbano.html Acesso em: 07 set. 2009.

. Cartografia da ação social: região latino-americana e novo desenvolvimento urbano. In: POGGIESE, Héctor; EGLER, Tamara T. C. (Orgs.). Otro desarrollo urbano: ciudad incluyente, justicia social e gestión democrática. Buenos Aires: CLACSO, 2009. (p. 147-156)

Pequena reflexão sobre categorias da teoria crítica do espaço: território usado, território praticado. In: RIBEIRO, Ana C. T. Por uma sociologia do presente - ação, técnica e espaço, v. 3, Rio de Janeiro: Letra Capital, 2013, p. 141-152.

RIBEIRO, Ana Clara T. et al. Por uma cartografia da ação: pequeno ensaio de método. Cadernos IPPUR - Planejamento e Território: ensaios sobre a desigualdade, ano XV, n. 2, p.33-5, ago./dez. 2001.

SANTANA, Lucycleide S. Os vazios urbanos nos centros de cidades como lugar para a habitação de interesse social: o caso de Maceió/AL. 2006, s/p. Dissertação. (Mestrado em Arquite- 
tura e Urbanismo). Faculdade de Arquitetura e Urbanismo da Universidade Federal de Alagoas, Maceió, 2006.

SANTOS, Milton; SILVEIRA, Maria L. O Brasil - Território e Sociedade no início do século XXI. Rio de Janeiro. São Paulo: Record, 2005. 475p.

SANTOS, Milton. O Espaço Dividido - os dois circuitos da economia urbana dos países subdesenvolvidos. 2 ed. São Paulo: Edusp, 2004. 440 p.

SILVA, Danielle; RÉGIA, Pricylla. Sem-teto prometem manter ocupação até transferência para conjunto habitacional. Alagoas 24horas, 03 nov. 2008. Disponível: http://www.alagoas24horas.com.br/conteudo/?vCod=55929 Acesso em: 24 nov. 2014.

SILVEIRA, Maria L. Ao território usado a palavra: pensando princípios de solidariedade socioespacial. In: VIANA, Ana L. d'Avila et al. (Orgs.). Saúde, desenvolvimento e território. Editora Hucitec. 2009, p. 127-150.

Submissão em: 28/01/2015

Revisão em: 15/02/2015

Aceite em 08/03/2015

Carlos Eduardo Nobre é geógrafo, mestre em Arquitetura e Urbanismo pela Universidade Federal de Alagoas e, atualmente, doutorando em Geografia pela Universidade Estadual de Campinas - UNICAMP. Pesquisa sobre o uso do território brasileiro pelo Programa Habitacional Minha Casa Minha Vida. Endereço para correspondência: Rua Nair Pimenta Silva, 915. Residencial Terra Nova, Barão Geraldo, Campinas-SP. CEP 13082-690.

E-mail: geocadu@gmail.com 